\title{
Antegrade Approach of Percutaneous Coronary Intervention for Chronic Total Occlusion
}

\author{
C. Raghu ${ }^{1}$ Rahul K. Ghogre ${ }^{1}$ Alekhya Mandepudi ${ }^{1}$ \\ ${ }^{1}$ Department of Cardiology, Aster Prime Hospital, Hyderabad, \\ Telangana, India
}

Ind J Car Dis Wom 2021;6:49-58.

\begin{abstract}
Address for correspondence C. Raghu, MD, DM, FACC, FESC, Department of Cardiology, Aster Prime Hospital, Hyderabad 500 016, Telangana, India (e-mail: raghu@drraghu.com).
\end{abstract}

\begin{abstract}
Keywords

- Antegrade dissection and reentry

- Antegrade approach

- Antegrade wire escalation

- Chronic total occlusion

Chronic total occlusion (CTO) is a common challenge accounting for $10 \%$ of coronary lesions found on coronary angiography. Patients are frequently referred for bypass surgery because percutaneous coronary intervention is challenging in this subset. Recent advances in the hardware as well as the technical expertise and an algorithm approach have improved the success to more than $90 \%$.

Antegrade approach is the cornerstone for managing СТО and has two distinct strategies: antegrade wire escalation, and antegrade dissection and reentry strategy. Step-wise approach to perform these procedures and the use of adjunct imaging are discussed.
\end{abstract}

Chronic total occlusion (CTO) of the coronary artery is defined as an occlusion of at least 1 month in duration, with angiographic thrombolysis in myocardial infarction flow grade 0 or 1 . They can be further classified as "early chronic" and "late chronic" if their age is less and more than 3 months, respectively. ${ }^{1}$

\section{Is There Evidence Supporting CTO Revascularization?}

1. For the relief of symptoms.

2. For those without symptoms when more than $10 \%$ area of myocardium has ischemia.

3. For reduction in the need for anti-angina medications. ${ }^{2}$

4. To reduce the need for coronary artery bypass surgery ( $C A B G)$, especially where CABG has been turned down either by the patient or the surgeon because of anticipated complications. ${ }^{3}$

5. After an angioplasty for the reduction of myocardial ischemia in patients with a large area of myocardium that is supplied by another vessel that is chronically occluded. ${ }^{4}$
6. For preservation of ejection fraction and improvement in functional class and natriuretic peptide levels. ${ }^{5}$

7. For safeguarding against future coronary events where revascularization of the CTO results in improved perfusion, myocardial contractility, and arrhythmia. ${ }^{6}$

8. For preventing worsening of events in case of an acute coronary syndrome in the future.

9. For patients with ischemia-dependent arrhythmias, who benefit from CTO revascularization. ${ }^{7}$

\section{What Are the Indications for СТО Recanalization?}

1. Where relief of exercise limiting angina or dyspnea is required.

2. Where there is a need to resolve ischemia detected by noninvasive stress testing.

3. Where improvement in regional ventricular function is diagnosed by cardiac magnetic resonance imaging with late contrast enhancement.

4. Where a considerable risk for future coronary disease progression is anticipated. ${ }^{8}$ published online April 13, 2021
DOI https://doi.org/

10.1055/s-0041-1728184 (c)2021. Women in Cardiology and Related Sciences.

This is an open access article published by Thieme under the terms of the Creative Commons Attribution-NonDerivative-NonCommercial-License, permitting copying and reproduction so long as the original work is given appropriate credit. Contents may not be used for commercial purposes, or adapted, remixed, transformed or built upon. (https://creativecommons.org/licenses/by-nc-nd/4.0/).

Thieme Medical and Scientific Publishers Pvt. Ltd. A-12, 2nd Floor, Sector 2, Noida-201301 UP, India 
Before attempting an angioplasty of a CTO lesion, documentation of collaterals to the distal segment is required. In the absence of collaterals, one needs to seriously consider assessing the viability of myocardium supplied by the chronically occluded segment.

The interventional techniques used to open such a CTO have advanced considerably over the past two decades, with the retrograde approach as an additional option. Still, the antegrade technique approach utilizing new wires and tools remains the primary approach in $90 \%$ of the cases ( - Fig. 1).

\section{What Are the Specific Objectives of Coronary Angiography in a CTO Lesion?}

Assessment of angiography has to be meticulous for appropriate planning of CTO percutaneous coronary intervention (PCI). A frame-by-frame review of all cine-angiographic runs of the occluded vessel is essential to determine proximal and distal segments, status of collaterals, CTO entry and exit points, length of lesion, calcification, and vessel course (-Fig. 2).

1. Length of the lesion: CTO length is an important characteristic that needs to be assessed. This is assessed by performing a bilateral simultaneous angiography of the coronaries allowing us to see the proximal and distal segments through the collaterals (-Fig. 3). This is especially important if the collaterals are from the contralateral side and remains the best way to exactly estimate the length of lesion. Bilateral simultaneous angiogram is important for an antegrade approach also. Using a $5 / 6$ French (Fr) guide catheter for the donor artery allows us to minimize the contrast volume and potential vascular complications.

2. Status of the distal vessel: The status of distal segment has to be obligatorily assessed as this allows the operator to have an idea of the course of the vessel in the invisible occluded segment so that the direction, progress, and control of guide wire can be maintained. Even for the most experienced CTO operator, an invisible distal segment remains contraindication for a $\mathrm{PCI}$ ( - Fig. 4).

3. Nature of the proximal segment: Anatomical characteristics of proximal segment help us to determine chances of success as well as strategy to be adopted. In case of flush ostial occlusion of coronary artery, the operator may prefer a retrograde approach as the primary strategy ( - Fig. 5).

4. Nature of collaterals: Differentiation of true lumen of a functional occlusion from an intravascular channel of bridging collateral is important because these collaterals can be easily occluded causing loss of distal vessel course, if wire manipulations are not gentle or unintentional. Multiple angiographic projections including bilateral simultaneous coronary angiography is needed to differentiate a microvascular false channel from a true lumen. In addition, a guide wire may be left in place at the time of bilateral simultaneous angiography to understand the course of the micro track ( - Fig. 6).

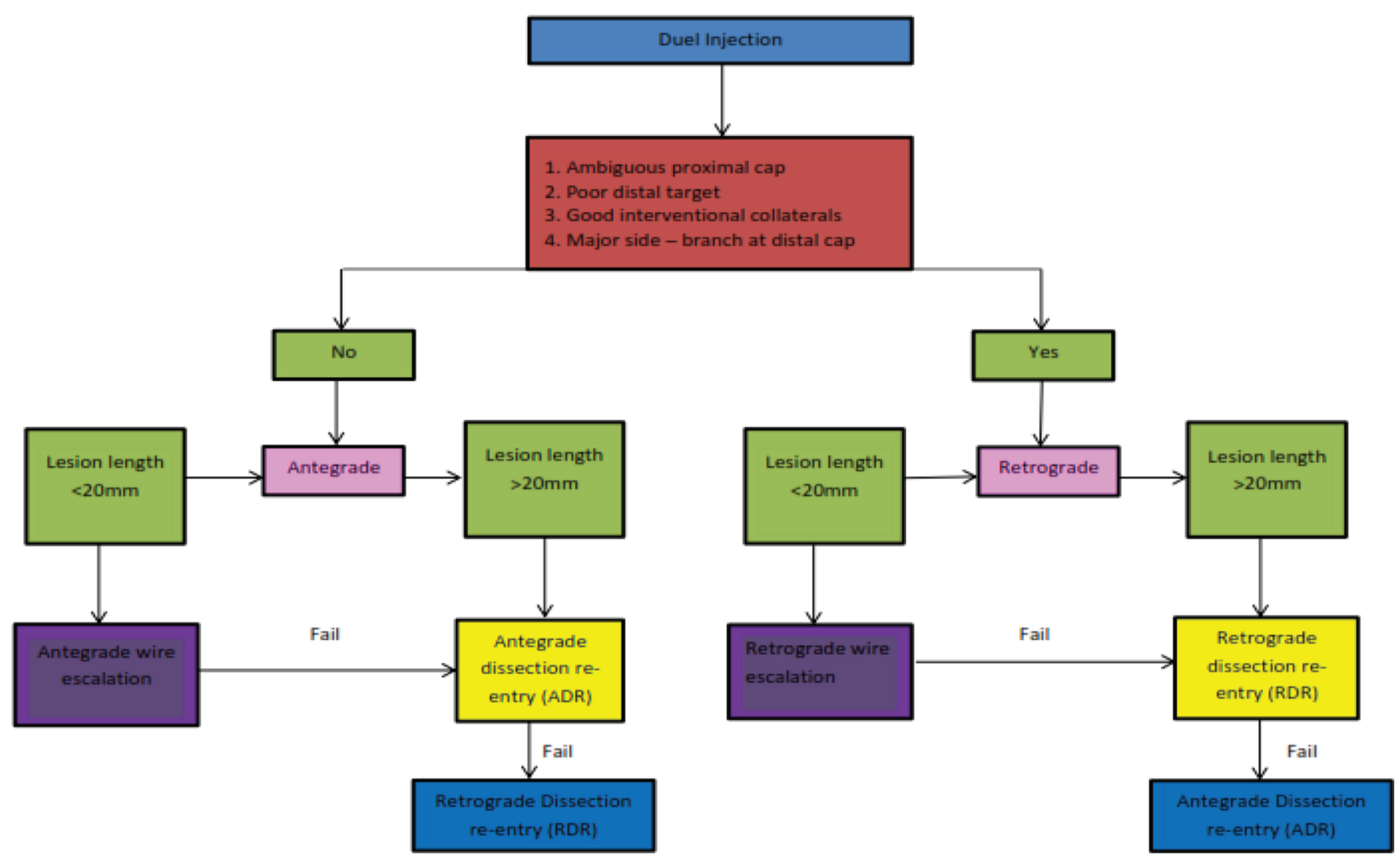

Fig. 1 Hybrid chronic total occlusion algorithm. 


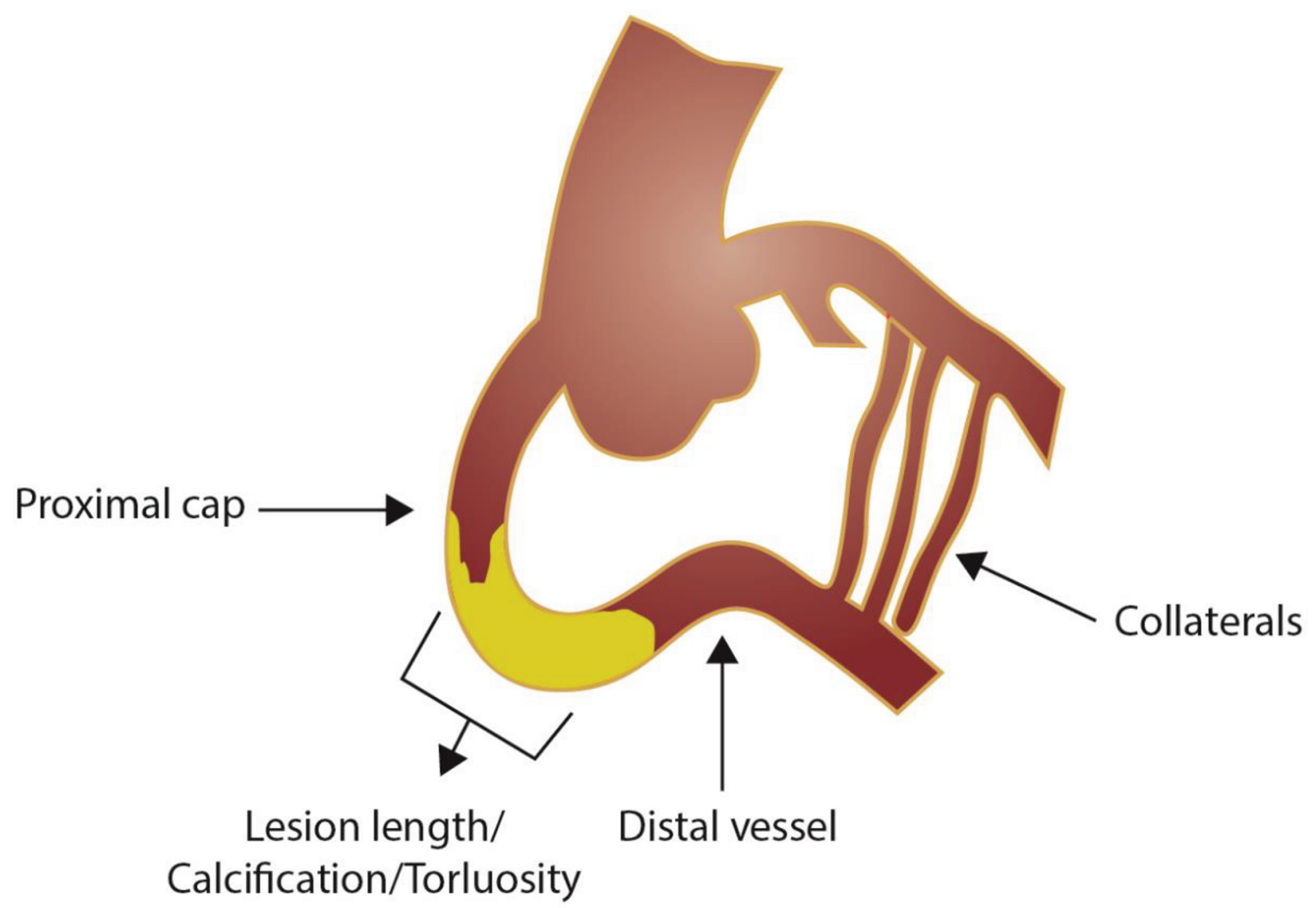

Fig. 2 Evaluation of specific features in chronic total occlusion lesion.

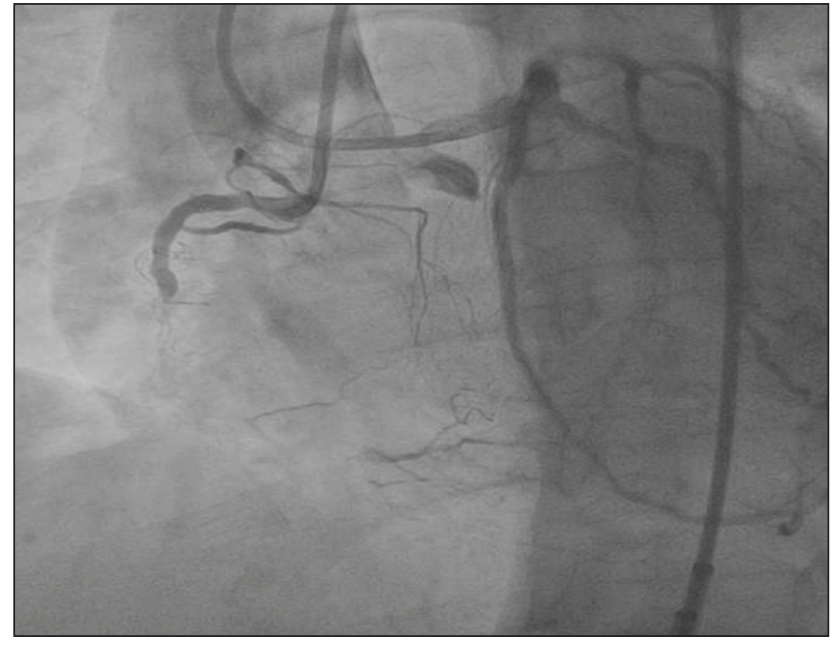

Fig. 3 Bilateral simultaneous coronary angiogram.

\section{How to Read a CTO Angiogram?}

CTO angioplasty procedure has to be performed as a planned procedure and not as an "ad-hoc." Proper strategy using a detailed angiography review is obligatory. A few tips adopted by experienced operators include:

1. Reading the angiogram at a slow speed in a frame-by-frame mode using the magnification feature when better detail is required.

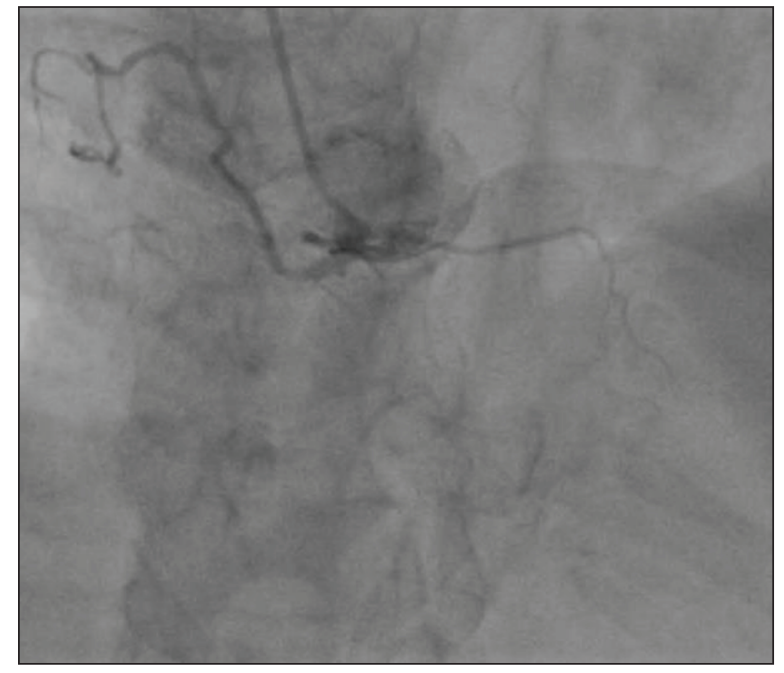

Fig. 4 Chronic total occlusion of the right coronary artery showing an invisible distal segment.

2. Detailed collateral mapping.

3. Image postprocessing techniques such as color inversion may help delineate collaterals better.

4. Additional computed tomography angiography may be needed in long-segment CTO lesions as this will help in deciphering the course of occluded vessel, presence and extent of calcification, and vessel tortuosity. 

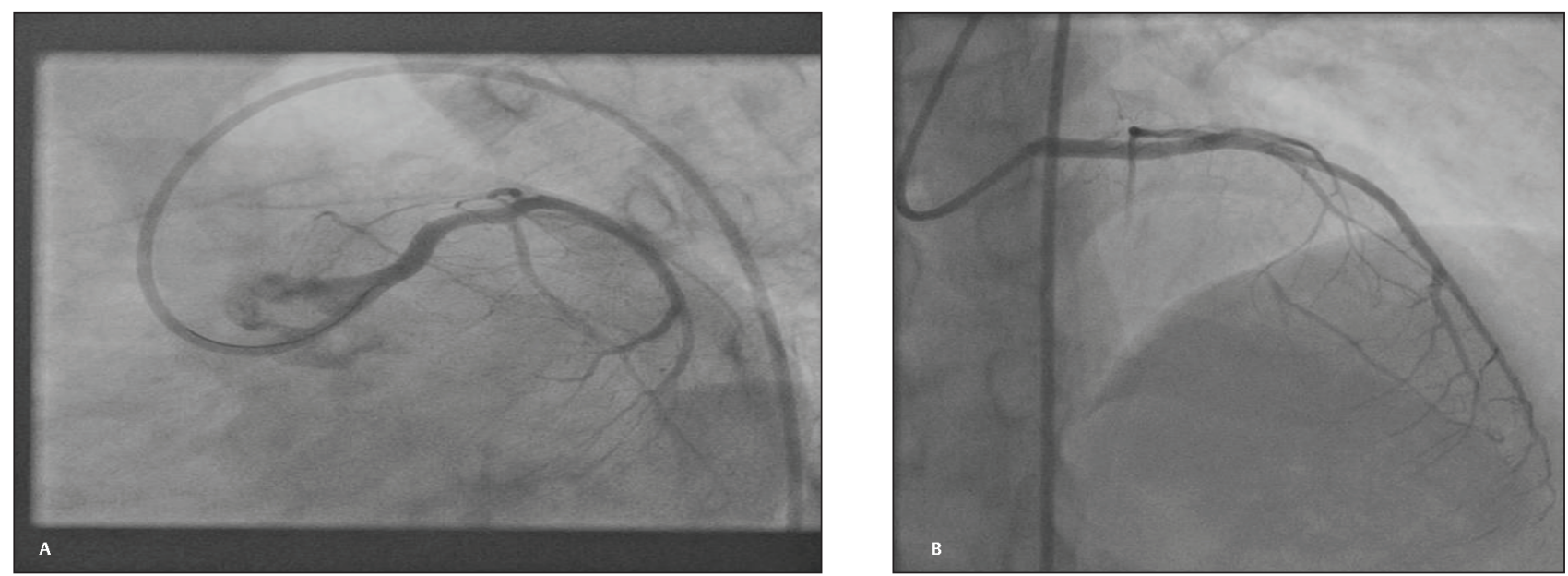

Fig. 5 Flush ostial occlusion of left anterior descending artery. (A) Left anterior oblique caudal view. (B) Anteroposterior cranial view.

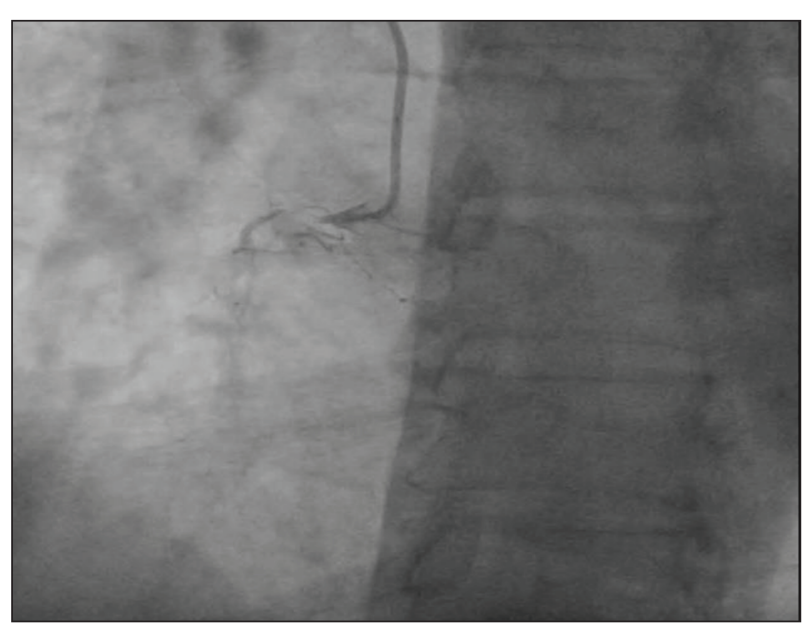

Fig. 6 Intravascular bridging collateral.

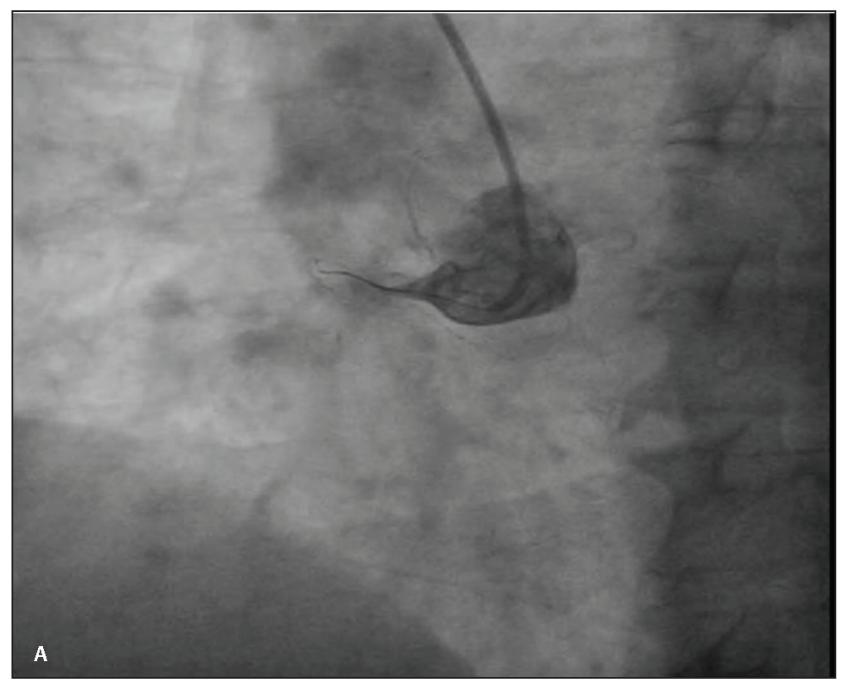

\section{How Does One Choose Primary Antegrade versus Retrograde Strategy?}

-Fig. 7 and -Table 1 provide case examples suitable for antegrade versus retrograde approach.

\section{When Is Antegrade CTO Revascularization Preferred?}

Antegrade CTO revascularization is the simple and most commonly used wire crossing technique. Nearly $70 \%$ of CTO interventions can be successfully recanalized using antegrade wire escalation (AWE). ${ }^{9}$ Operators need to be familiar and confident with antegrade recanalization as this forms the foundation for other complex CTO revascularization including antegrade dissection and reentry (ADR) and retrograde techniques.

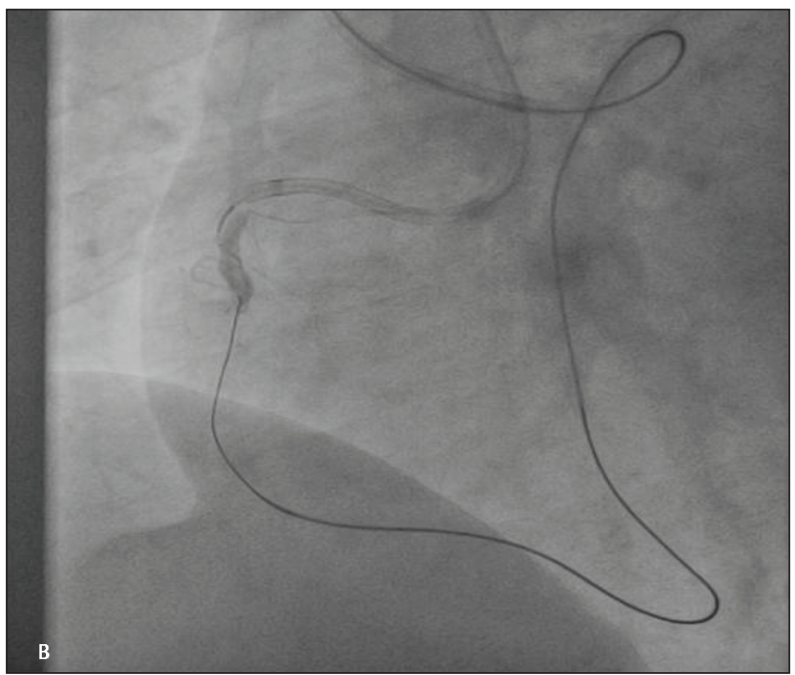

Fig. 7 Case example suitable for antegrade versus retrograde approach. (A) Antegrade wire escalation. (B) Retrograde wire escalation. 
Table 1 Primary antegrade versus retrograde strategy

\begin{tabular}{|l|l|}
\hline Antegrade approach & Retrograde approach \\
\hline - Nonambiguous proximal & - Occlusions with “interven- \\
$\begin{array}{l}\text { cap } \\
\text { - Goonal" collaterals } \\
\text { - Lesion length landing zone }<20 \mathrm{~mm}\end{array}$ & $\begin{array}{l}\text { - Diseased landing zone } \\
\text { - Bifurcation at distal cap } \\
\text { - Proximal cap ambiguity }\end{array}$ \\
\hline
\end{tabular}

- Antegrade revascularization is most successful in following cases:

- When length of the occlusions is $<20 \mathrm{~mm}$.

- In straight long-segment occlusion.

- In the presence of a microchannel.

- In cases of in-stent restenosis.

\section{What Are the Various Antegrade Revascularization Strategies for CTO Revascularization?}

1. AWE strategy.

2. ADR strategy.

AWE strategy remains the predominant antegrade CTO PCI strategy, being performed in approximately three-quarters of cases. $^{10}$

\section{What Is AWE Strategy?}

In AWE strategy, the wire remains within the lumen during the entire procedure and does not go subintimal. In the ADR strategy, the wire is intentionally advanced in the subintimal plane and brought back into the lumen. The development of dedicated CTO hardware, better understanding of the CTO pathology, operator expertise, and evolution of hybrid algorithm have led to success rates of more than $90 \%$ in the contemporary era with antegrade strategy. AWE strategy accounts for $75 \%$ of CTO PCI techniques.
Why Is AWE Preferred over ADR Strategy?

A true-to-true lumen strategy is preferred because of less vascular injury. There are lower chances of side branch occlusion and periprocedural myocardial infarction. However, there is lack of clarity about the clinical significance of these findings as to date no studies have shown superiority of these findings.

\section{Which Lesions Are Suitable for AWE Strategy?}

- Nonambiguous proximal cap.

- Good distal landing zone.

- Lesion length $<20 \mathrm{~mm}$.

\section{What Are the Steps in AWE Strategy of CTO} Revascularization?

Steps for AWE strategy have also been listed in - Table 2. AWE consists of the following steps:

1. Using a microcatheter or over-the-wire (OTW) balloon for enhanced guide wire support ( - Fig. 8): This plays a key role during antegrade crossing in all CTOs for the following reasons:

- Increases penetration power of the wire.

- The wire tip can be reshaped to increase the success of the crossing while retaining its position.

Table 2 Steps for antegrade wire escalation

\begin{tabular}{|l|l|}
\hline Step 1 & Choosing a microcatheter \\
\hline Step 2 & Advancing the microcatheter to chronic total occlusion \\
\hline Step 3 & Selection of a guide wire \\
\hline Step 4 & Guide wire is shaped \\
\hline Step 5 & $\begin{array}{l}\text { Guide wire is advanced by sliding, drilling, penetration, } \\
\text { or a combination }\end{array}$ \\
\hline Step 6 & Wire position is assessed \\
\hline Step 7 & True lumen balloon angioplasty and stenting \\
\hline
\end{tabular}

\section{(A) $30^{\circ} 1 \mathrm{~mm}$ bent}

\section{(B) For re-entering into the true lumen from the subintimal space}

Fig. 8 Wire shaping for proximal cap penetration with the help of microcatheter. 
- Exchange of coronary guide wires is simpler.

- Avoids wire twisting during parallel wire technique.

2. Reaching the CTO: Here, using a soft guide wire supported by microcatheter or OTW balloon to reach the proximal CTO cap rather than using a high-penetration and tapered-tip dedicated CTO guide wire is important because:

- It limits risk of vessel injury.

- The primary curve required to reach the CTO proximal cap is usually much larger and different from that used to cross the CTO segment, which is smaller (-Fig. 9).

After reaching the proximal cap, certain operators remove the workhorse guide wire and contrast is injected through the microcatheter to clearly delineate the characteristics of the CTO proximal cap.

3. Choosing coronary guide wire for CTO crossing: Selecting the appropriate guide wire is most important for initial antegrade CTO crossing. A tapered, polymer-jacketed wire (Fielder XT, Fielder XT-A, Fielder XT-R [Asahi Intecc]) is usually used to track the microchannel. If this wire fails to cross CTO, and the course of the vessel is well understood, then a stiff, tapered-tip guide wire (Gaia 2nd [Asahi Intecc]) is preferred. If CTO course is unclear, a polymer-jacketed guide wire (Pilot 200 [Abbott Vascular]) or moderate stiffness, nontapered guide wire (Ultimate Bros 3 [Asahi Intecc]) is preferred, because it is more likely to track CTO vessel architecture.

4. Guide wire tip shaping: Shaping the tip of wire helps to maximize the likelihood of successful CTO crossing.
A small (1 mm long, 30-40 degrees) distal bending is preferred for the following reasons:

- Enhances the penetration capability of guide wire.

- Facilitates entry into the microchannel.

- Improves ability to steer guide wire within tight spaces like CTO segment.

- Reduces chances of wire traversing outside vessel architecture or into branches within the CTO segment.

5. Advancing the guide wire techniques: Guide wire handling techniques like sliding, drilling, or penetration are used for both CTO and non-CTO occlusions.

- Sliding: Initial step for CTO crossing is sliding. In this, tapered, polymer-jacketed guide wire moves forward to track the channel by gentle probing and rotation within the CTO segment.

- Drilling: During drilling the wire is rotated in a controlled fashion in both directions. The degree of rotation of the guide wire should be less than 90 degrees in each direction.

- Penetration: The CTO can be crossed under the following steps:

- To cross the proximal cap.

- Navigating through occlusion.

- Distal entry into true lumen.

6. Assess wire position: Determining the guide wire position after CTO crossing helps to prevent perforation. Guide wire location can be ascertained by the following ways:

- Contralateral injection.

- Sudden, spontaneous free movement of the wire tip.

- Distal wiring with workhorse guide wire after exchange.

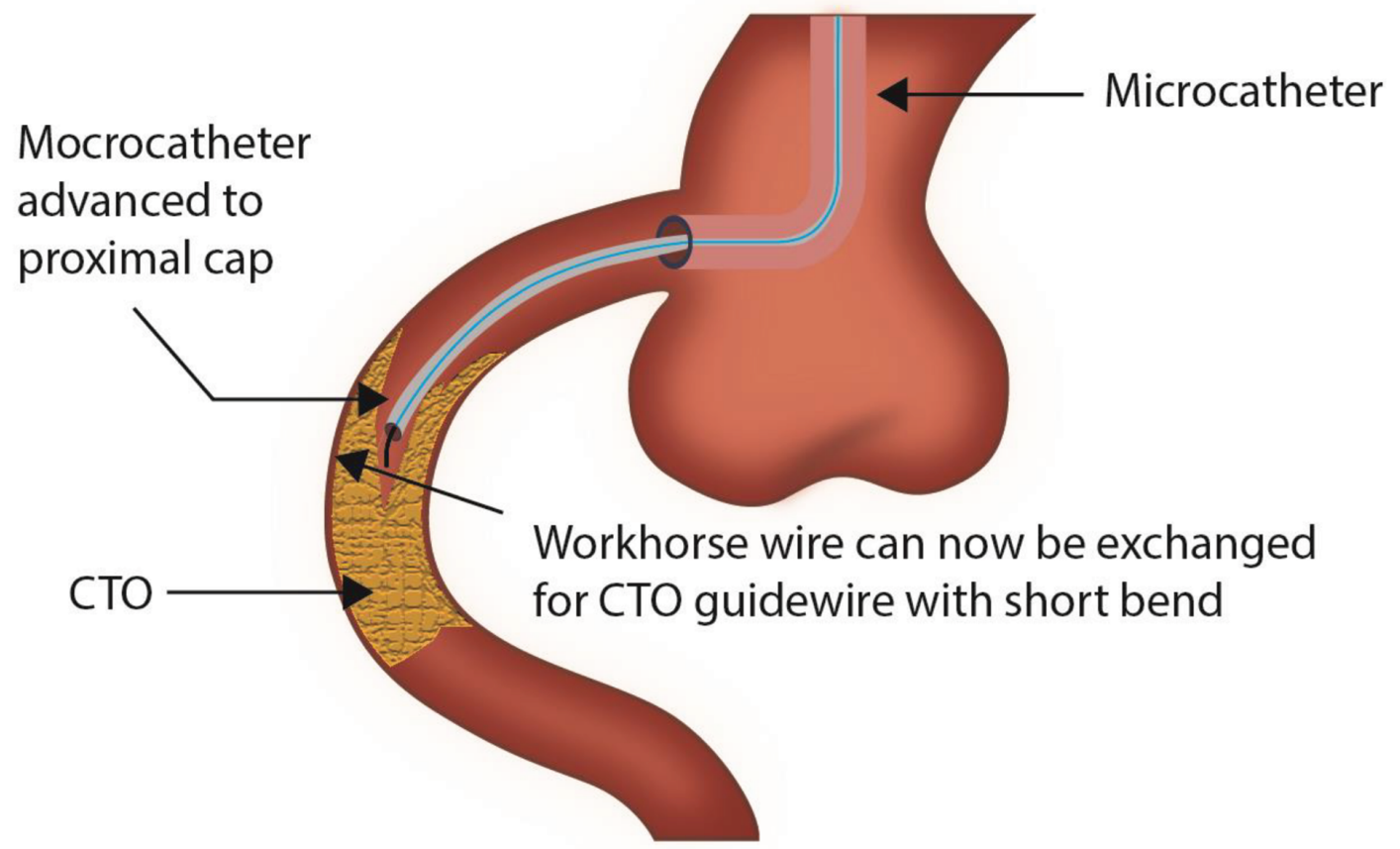

Fig. 9 Exchange of the workhorse guide wire for a chronic total occlusion (CTO) crossing guide wire with a short tip. 
- Aspirating blood through microcatheter.

- For defining vessel architecture, we can use either intravascular ultrasound (IVUS) or contrast injection.

7. Outcomes that can potentially happen after guide wire advancement within the occlusion:

- Distal lumen crossing.

- Subintimal space crossing.

- Exiting out of the vessel architecture.

\section{What Is the Guide Catheter Setup for Antegrade CTO PCI?}

1. CTO vessel: Currently, most CTO operators use a 7Fr guide catheter with a larger inner diameter to perform CTO PCI. In addition, a recent preference for bilateral radial access to reduce vascular complications is also being noted widely. ${ }^{11}$

2. Contralateral donor vessel: After coronary engagement with the guide catheter, it is preferred to place a workhorse coronary guide wire in the donor coronary artery. The advantages of having a coronary guide wire include stability of the guide catheter position, enabling of quick engagement and disengagement, as well as immediate treatment in case of donor vessel injury. Donor vessel injury can result in rapid deterioration when there is a contralateral CTO.

\section{Guide Catheter Support}

Guide catheter support can backup not only the wire passage, but also stent and balloon advancement.

Large-diameter guide catheters provide improved support, even with a routine curve such as Judkin's right. In addition, they provide a good amount of working space for complex techniques such as anchoring balloon, IVUS imaging guidance, and double wire. Appropriate guide catheter support is especially important for ostial and proximal occlusions, where a deeper engagement is not possible.

Proper alignment of guide catheter is crucial for lesions close to the ostium of the right coronary artery. In case of nonostial lesions, one can use a smaller guide catheter $(6 \mathrm{Fr})$ to enable deep canulation.

\section{Microcatheter Support}

Microcatheter support usage with the OTW technique is strongly recommended, as it facilitates the wire manipulation.

When placing a microcatheter at the proximal end of the СТО, a softer wire that has been introduced initially would be exchanged for a dedicated CTO wire. This would protect the proximal artery from any damage.

Apart from low-profile (LP) microcatheters, there are specific support catheters to help wire manipulation or for assistance during the PCI. In double-lumen microcatheter, one wire is guided through the central lumen as in typical OTW fashion and the second wire exits through other port with shorter rapid exchange lumen.

\section{Microcatheter versus Over-The-Wire Balloon}

Microcatheter-supported advancement of coronary wire is mandatory in all CTO PCI. OTW balloon is an alternative with the advantage of a smaller tip profile. However, in the microcatheter, tip marker is very close to the tip and identifies its position. In the OTW balloons, the central marker of a 1.0 to $1.5 \mathrm{~mm}$ balloon does not serve as a marker for the tip location in CTO. Other major advantages and limitations have been enlisted in - Table 3 .

\section{Which Coronary Guide Wires for AWE Strategy?}

It is essential to understand the characteristics of various guide wires for successful AWE. Previously, an escalation of the tip load of a coronary guide wire used to be the strategy, but currently the choice of wire depends on the duration of CTO and the proximal cap characteristics.

1. Tapered proximal cap: This СТO morphology has the highest chances of success; hence a low- or medium-tip wire with polymer jacket is used. Tapered proximal cap has relatively low resistance and the coronary guide wire can traverse the loose tissue within the CTO body with a

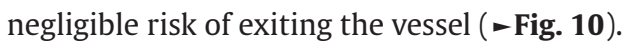

2. Blunt proximal cap: Blunt proximal cap with heavy calcification, presence of side branch at CTO level or bridging collaterals, and a high tip load penetrating wire, for example, Confianza Pro 12 (Asahi Intecc), is chosen for a short-segment CTO that has little tortuosity within the CTO body. The major limitation of this wire is that it can easily exit the vessel and hence is not suitable for long, tortuous, and ambiguous CTO body ( - Fig. 11).

Coronary guide wires along with their distinct characteristics as well as dedicated utility in different subsets are documented in $\mathbf{- T a b l e ~} \mathbf{4}$. Characteristics of individual wires in detail are not being discussed in this article.

Table 3 Advantages of microcatheter over the over-the-wire balloon

\begin{tabular}{|l|l|l|}
\hline & Microcatheter & Over-the-wire balloon \\
\hline Advantages & $\begin{array}{l}\text { - Smaller profile } \\
\text { - Larger internal } \\
\text { diameter; allows } \\
\text { better wire torque } \\
\text { - Marker at tip allows } \\
\text { for exact positioning } \\
\text { - Resistant to kinking }\end{array}$ & $\begin{array}{l}\text { Balloon inflation can } \\
\text { be performed with- } \\
\text { out exchange }\end{array}$ \\
\hline
\end{tabular}

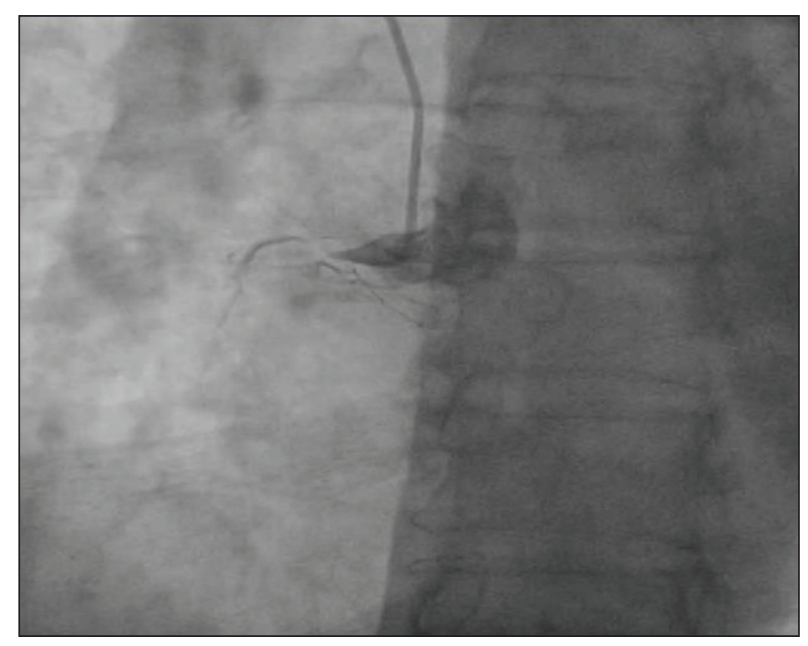

Fig. 10 Chronic total occlusion proximal cap-tapered. 


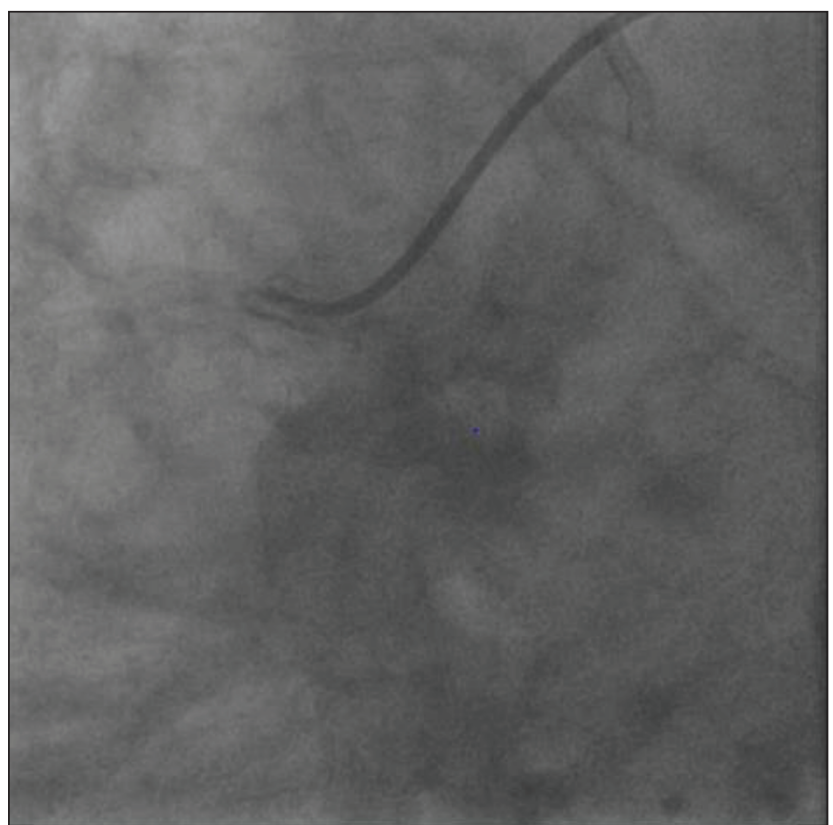

Fig. 11 Chronic total occlusion proximal cap-blunt.

Table 4 Guide wires for antegrade recanalization strategy

\begin{tabular}{|c|c|c|}
\hline $\begin{array}{l}\text { Wire } \\
\text { properties }\end{array}$ & $\begin{array}{l}\text { Representative } \\
\text { examples }\end{array}$ & Functions \\
\hline \multirow{3}{*}{$\begin{array}{l}\text { Low-gram } \\
\text { weight; } \\
\text { tapered tip; } \\
\text { polymer jacket }\end{array}$} & $\begin{array}{l}\text { Fielder XT (Asahi } \\
\text { Intecc) }\end{array}$ & \multirow{3}{*}{$\begin{array}{l}\text { Palpate proximal cap; } \\
\text { loose tissue tracking within } \\
\text { chronic total occlusion } \\
\text { (CTO) body; knuckle wire }\end{array}$} \\
\hline & $\begin{array}{l}\text { Fielder XT-A } \\
\text { (Asahi Intecc) }\end{array}$ & \\
\hline & $\begin{array}{l}\text { Fielder XT-R } \\
\text { (Asahi Intecc) }\end{array}$ & \\
\hline \multirow{3}{*}{$\begin{array}{l}\text { Medium-gram } \\
\text { weight; poly- } \\
\text { mer jacket }\end{array}$} & $\begin{array}{l}\text { Pilot } 200 \\
\text { (Abbott) }\end{array}$ & \multirow{3}{*}{$\begin{array}{l}\text { Palpate proximal cap; } \\
\text { tracking within more } \\
\text { resistant CTOs; knuckle } \\
\text { wire; less likely to exit in } \\
\text { tortuosity and ambiguity }\end{array}$} \\
\hline & $\begin{array}{l}\text { Gladius (Asahi } \\
\text { Intecc) }\end{array}$ & \\
\hline & $\begin{array}{l}\text { Crosswire NT } \\
\text { (Terumo) }\end{array}$ & \\
\hline \multirow{3}{*}{$\begin{array}{l}\text { Medium-gram } \\
\text { weight; no pol- } \\
\text { ymer jacket }\end{array}$} & $\begin{array}{l}\text { Gaia } 2 \text { (Asahi } \\
\text { Intecc) }\end{array}$ & \multirow{3}{*}{$\begin{array}{l}\text { Crossing CTO body in } \\
\text { more mature resistant } \\
\text { lesions; tactile feedback } \\
\text { and torque transmission } \\
\text { help in understanding } \\
\text { anatomy }\end{array}$} \\
\hline & $\begin{array}{l}\text { Gaia } 3 \text { (Asahi } \\
\text { Intecc) }\end{array}$ & \\
\hline & $\begin{array}{l}\text { Gaia Next (Asahi } \\
\text { Intecc) }\end{array}$ & \\
\hline \multirow{2}{*}{$\begin{array}{l}\text { High-gram } \\
\text { weight; } \\
\text { tapered; no } \\
\text { polymer jacket }\end{array}$} & $\begin{array}{l}\text { Confianza Pro } 12 \\
\text { (Asahi Intecc) }\end{array}$ & \multirow{2}{*}{$\begin{array}{l}\text { Penetration wires for } \\
\text { focused crossing of highly } \\
\text { resistant segments }\end{array}$} \\
\hline & $\begin{array}{l}\text { Progress 200T } \\
\text { (Abbott) }\end{array}$ & \\
\hline $\begin{array}{l}\text { Dedicated } \\
\text { knuckle wire }\end{array}$ & $\begin{array}{l}\text { Gladius MG } \\
\text { (Asahi Intecc) }\end{array}$ & $\begin{array}{l}\text { Crossing long segments } \\
\text { efficiently using blunt } \\
\text { dissection, with a low risk } \\
\text { of perforation }\end{array}$ \\
\hline \multirow{3}{*}{$\begin{array}{l}\text { Collateral } \\
\text { crossing wires } \\
\text { for retrograde } \\
\text { procedures }\end{array}$} & $\begin{array}{l}\text { Sion (Asahi } \\
\text { Intecc) }\end{array}$ & \multirow{3}{*}{$\begin{array}{l}\text { Low tip load, high torque, } \\
\text { and flexible shafts to adapt } \\
\text { to channel shapes }\end{array}$} \\
\hline & $\begin{array}{l}\text { Sion Black (Asahi } \\
\text { Intecc) }\end{array}$ & \\
\hline & $\begin{array}{l}\text { Suoh03 (Asahi } \\
\text { Intecc) }\end{array}$ & \\
\hline
\end{tabular}

\section{How to Cross the CTO Body after Penetrating the Proximal Cap?}

\section{Escalation/De-Escalation Therapy}

The overriding principle of СТO angioplasty is procedure safety, which can be achieved with this strategy. After the proximal cap has been penetrated, the microcatheter has to be advanced into the CTO body and the penetrating wire needs to be exchanged with a workhorse wire. Penetrating wires have a tendency to exit the vessel architecture, which usually has little clinical consequences; but if a secondary device like balloon, Rotablator, etc. is introduced, it can have catastrophic consequences. So before advancing a secondary device, the wire position has to be confirmed by taking multiple orthogonal projections as well as contralateral injection from the donor vessel to opacify the distal vessel through the retrograde collaterals. It is important to avoid antegrade injections as they yield little information and may further propagate coronary dissection in case the wire has passed through a subintimal plane. Once the luminal position of the distal wire has been confirmed, the wire is de-escalated with a soft-tip wire for the remaining procedure.

\section{What Is the Role of IVUS in CTO PCI?}

IVUS helps in stent sizing, stent apposition and expansion, and optimizes the angioplasty results. ${ }^{12}$ It is preferred over optical coherence tomography for CTO PCI as it obviates the need for antegrade high-pressure contrast injection. In addition, IVUS can determine the location of CTO stump, the wire course, and its location, especially when it is in the subintimal plane, as well as its relation to the side branches. ${ }^{13}$

\section{Antegrade Dissection and Reentry Strategy}

Primary ADR strategy is used when there is a CTO segment with the proximal cap that is well defined, long-length CTO with a clear-cut landing zone proximal to important side branches. ${ }^{14}$

The Cross Boss and Stingray system (Boston Scientific) is an important advancement for the ADR strategy. The Cross Boss is a blunt-tipped dissection catheter that will track through intimal plaque or create a controlled extra plaque dissection that facilitates delivery of the Stingray LP balloon beyond the distal cap.

During ADR strategy, the proximal cap is crossed using a knuckled guide wire supported by a microcatheter through the CTO body segment. The last 20 to $30 \mathrm{~mm}$ of the CTO segment is dissected using the Cross Boss system. The Stingray LP balloon is then inflated with its correct orientation decided on fluoroscopy for reentry. Since the Stingray wire has a small micro barb at the tip, reentry into the healthy distal landing zone has become easier. This may not be effective when there is a large burden of atheroma between the Stingray balloon and the lumen in which case operators use a tapered penetration wire (e.g., Confianza Pro 12 or Astato 8/20 [Asahi Intecc]) instead of the Stingray wire. Once the distal lumen has been accessed, the penetration wire is exchanged for a workhorse wire to ensure a safe procedure. 
In case the wire inadvertently passes into a dissection plane and beyond the distal cap during AWE, it is advocated for early bailout ADR strategy. The Cross Boss is not required in this setting but instead a Stingray LP system using a Miracle Bros 12 wire (Asahi Intecc) is used to reach the distal lumen. ${ }^{15}$

\section{What to Do If the Wire Has Crossed But the Balloon Is Unable to Cross?}

The strategies to be employed in such a scenario can be classified into:

1. First-line strategies.

2. Second-line strategies.

3. Third-line strategies. ${ }^{16}$

These have been elaborated in - Table 5 .

\section{What to Do in Case of Undilatable Lesions?}

In case of undilatable lesions, the steps outlined in - Table 6 can be taken. ${ }^{17}$

\section{When to Stop a CTO PCI?}

CTO PCI has increased chances of complications compared with a non-CTO PCI. It is important to accept failure rather than pursue aggressive strategies that can potentially lead to serious complications. It is advisable to stop the procedure under the following circumstances:

- Development of complication.

- High radiation dose (>5 Gy).

- Large contrast volume(3.7× estimated creatinine clearance).

- Unable to cross lesion after exhausting all options.

- Physician or patient fatigue. ${ }^{17}$

Table 5 Strategies for balloon uncrossable lesions

\begin{tabular}{|c|c|c|}
\hline $\begin{array}{l}\text { First-line } \\
\text { strategies }\end{array}$ & $\begin{array}{l}\text { Second-line } \\
\text { strategies }\end{array}$ & $\begin{array}{l}\text { Third-line } \\
\text { Strategies }\end{array}$ \\
\hline $\begin{array}{l}\text { Guide catheter } \\
\text { support }\end{array}$ & $\begin{array}{l}\text { Balloon-assisted } \\
\text { microdissection; } \\
\text { advancing a } \\
\text { low-profile balloon } \\
\text { and intentionally } \\
\text { rupturing the } \\
\text { balloon adjacent to } \\
\text { the lesion. }\end{array}$ & \multirow[t]{5}{*}{ ADR strategy } \\
\hline $\begin{array}{l}\text { Balloon selection: } \\
\text { semi-compliant } \\
\text { low-profile balloon }\end{array}$ & $\begin{array}{l}\text { Excimer laser coro- } \\
\text { nary atherectomy }\end{array}$ & \\
\hline $\begin{array}{l}\text { Guide catheter } \\
\text { extensions } \\
\text { - Guideliner } \\
\text { (Vascular } \\
\text { Solutions) } \\
\text { - Guidezella } \\
\text { (Boston } \\
\text { Scientific) } \\
\text { - Telescope } \\
\text { (Medtronic) }\end{array}$ & \multirow[t]{3}{*}{$\begin{array}{l}\text { High-speed rota- } \\
\text { tional atherec- } \\
\text { tomy and orbital } \\
\text { atherectomy }\end{array}$} & \\
\hline $\begin{array}{l}\text { Anchoring balloon } \\
\text { techniques }\end{array}$ & & \\
\hline $\begin{array}{l}\text { Use of low-profile } \\
\text { microcatheter }\end{array}$ & & \\
\hline
\end{tabular}

Table 6 Strategies for undilatable lesions

\begin{tabular}{|l|}
\hline 1. Noncompliant (NC) balloons \\
\hline 2. Ultrahigh-pressure NC balloons \\
\hline 3. Cutting/scoring balloons \\
\hline 4. Excimer laser coronary atherectomy \\
\hline 5. Rotational atherectomy \\
\hline 6. Intravascular lithotripsy \\
\hline
\end{tabular}

\section{Conclusion}

Contemporary success of antegrade CTO PCI has improved dramatically due to operators' technical dexterity and advances in hardware technology. To achieve high success rate, operators need to have a clear understanding of both these issues. AWE remains the predominant strategy for crossing short CTOs of lower complexity. But in cases of complex CTOs, an ADR strategy is a safe and effective alternative.

\section{Source of Funding}

No funding obtained.

\section{Conflict of Interest}

None.

\section{References}

1 Yalonetsky S, Osherov AB, Strauss BH, The pathobiology of CTO. In: Waksman R, Saito S, eds. Chronic Total Occlusions: A Guide to Recanalization. 2nd Ed. Chichester: Wiley Blackwell; 2013:3-8

2 Rossello X, Pujadas S, Serra A, et al. Assessment of inducible myocardial ischemia, quality of life, and functional status after successful percutaneous revascularization in patients with chronic total coronary occlusion. Am J Cardiol 2016; 117(5):720-726

3 Azzalini L, Torregrossa G, Puskas JD, et al. Percutaneous revascularization of chronic total occlusions: rationale, indications, techniques, and the cardiac surgeon's point of view. Int J Cardiol 2017;231:90-96

4 Safley DM, Koshy S, Grantham JA, et al. Changes in myocardial ischemic burden following percutaneous coronary intervention of chronic total occlusions. Catheter Cardiovasc Interv 2011; 78(3):337-343

5 Cardona M, Martín V, Prat-Gonzalez S, et al. Benefits of chronic total coronary occlusion percutaneous intervention in patients with heart failure and reduced ejection fraction: insights from a cardiovascular magnetic resonance study. J Cardiovasc Magn Reson 2016;18(1):78

6 Claessen BE, Dangas GD, Weisz G, et al. Prognostic impact of a chronic total occlusion in a non-infarct-related artery in patients with ST-segment elevation myocardial infarction: 3-year results from the HORIZONS-AMI trial. Eur Heart J 2012; 33(6):768-775

7 Raja V, Wiegn P, Obel O, et al. Impact of chronic total occlusions and coronary revascularization on all-cause mortality and the incidence of ventricular arrhythmias in patients with ischemic cardiomyopathy. Am J Cardiol 2015;116(9):1358-1362

8 Werner GS. Tools \& techniques: the antegrade recanalisation technique for CTO. EuroIntervention 2011;6(9):1137-1139

9 Maeremans J, Walsh S, Knaapen P, et al. The hybrid algorithm for treating chronic total occlusions in Europe: the RECHARGE registry. J Am Coll Cardiol 2016;68(18):1958-1970 
10 Galassi AR, Werner GS, Boukhris M, et al. Percutaneous recanalisation of chronic total occlusions: 2019 consensus document from the EuroCTO Club. EuroIntervention 2019;15(2): 198-208

11 Bakker EJ, Maeremans J, Zivelonghi C, et al. Fully transradial versus transfemoral approach for percutaneous intervention of coronary chronic total occlusions applying the hybrid algorithm: insights from RECHARGE Registry. Circ Cardiovasc Interv 2017;10(9):e00525

12 Hong SJ, Mintz GS, Ahn CM, et al; IVUS-XPL Investigators. Effect of intravascular ultrasound-guided drug-eluting stent implantation: 5-year follow-up of the IVUS-XPL randomized trial. JACC Cardiovasc Interv 2020;13(1):62-71

13 Maeremans J, Avran A, Walsh S, et al; RECHARGE Investigators. One-year clinical outcomes of the hybrid CTO revascularization strategy after hospital discharge: a sub-analysis of the multicenter RECHARGE registry. J Invasive Cardiol 2018;30(2): 62-70

14 Walsh SJ, Cosgrove C, Spratt JC, Hanratty CG. A technical focus on antegrade dissection and re-entry for coronary chronic total occlusions: a practice update for 2019. Korean Circ J 2019; 49(7):559-567

15 CreaneyC,WalshSJ.Antegradechronictotalocclusionstrategies: a technical focus for 2020. Interv Cardiol 2020;doi: 10.15420/ icr.2020.05, www.ICRjournal.com

16 McQuillan C, Jackson MWP, Brilakis ES, Egred M. Uncrossable and undilatable lesions-a practical approach to optimizing outcomes in PCI. Catheter Cardiovasc Interv 2021;97(1):121-126

17 Tajti P, Brilakis ES. Chronic total occlusion percutaneous coronary intervention: evidence and controversies. J Am Heart Assoc 2018;7(2):e006732 